\title{
O controle da administração pública pela cidadania
}

\author{
Irma Sueli Oricolli ${ }^{1}$
}

\section{Resumo}

\begin{abstract}
O presente artigo dispõe sobre a necessidade legal do controle dos atos da Administração Pública e examina os mecanismos trazidos pela Constituição Federal para a sua realização. Expõe a necessidade do cidadão refletir sobre o conceito jurídico de cidadania e o seu exercício efetivo, o qual lhe permitirá a iniciativa, também legal, de controlar a Administração Pública. Enumera e define os instrumentos trazidos pela Lei Maior no tocante a participação popular e, por fim, comenta a atuação dos Tribunais de Contas, mencionando sua relevante importância para que o controle dos atos da Administração Pública seja eficaz e o seu significativo papel quando provocado pelo cidadão. Evoca a necessidade de maior divulgação das informações sobre o assunto por todos os meios de comunicação, bem como pelos entes dos três poderes da União. Conclui com a conclamação do cidadão à Democracia, exercendo, por direito e por dever, a sua Cidadania junto às entidades que regem a Nação.
\end{abstract}

Palavras-Chave: Controle da Administração; Cidadania; Participação Popular; Tribunal de Contas.

\section{Introdução}

Na proposta do presente trabalho, constante de projeto de pesquisa do Curso de Especialização em Direito do Estado, encaminhado à Universidade Estadual de Londrina, se propôs como objetivo geral a avaliação das formas de controle da Administração Pública, considerando o efetivo exercício da cidadania, cujo conceito jurídico tratar-se-ia nos objetivos específicos, como assim se fez, além de provocar àqueles que dele fizerem a leitura, a reflexão sobre esse exercício, de tal sorte que tal análise tivesse o condão de incentivar que as pessoas humanas, titulares de direitos e deveres, se colocassem no papel de cidadãos.

O projeto foi elaborado num momento da história brasileira em que ainda não havia ocorrido o referendo sobre o porte de armas. As CPIs para apuração do envolvimento de parlamentares com falcatruas, "mensalões", "mensalinhos", transportes de dólares, "caixa dois" e outros tantos episódios que levaram o cidadão brasileiro à revolta e ao

1 Especialista em Direito do Estado - Direito Administrativo pela Universidade Estadual de Londrina. 
inconformismo, também não haviam emergido. Certamente após esse período, o Brasil é outro e, agora, mais do que nunca, se espera do cidadão brasileiro uma tomada de posição quanto ao controle da Administração Pública, o que se acredita será visto nos próximos anos.

A necessidade do despertar de lideranças sadias e responsáveis por levar informações que propiciem ao cidadão conhecer a Constituição do Brasil e dela fazer uso, se torna cada vez mais premente. Somente as informações permitirão que o indivíduo, que tem em sua proteção o princípio da garantia da dignidade da pessoa humana, conduza, no exercício da cidadania, a gestão dos administradores da coisa pública.

Este artigo demonstra como se pode dar o controle das atividades do Estado, mediante institutos constitucionais, bem como leva o leitor a descobrir a existência de outras formas de exercer tal controle, mediante a sua própria participação e utilização de tais institutos, tão pouco comentados e informados.

\section{0 controle da administração}

É sabido, pois, que a Administração Pública, no exercício de suas funções, se sujeita, além do autocontrole, ao controle por parte dos poderes Legislativo e Judiciário, com a finalidade de assegurar a sua atuação em consonância com os princípios que lhe são impostos pelo ordenamento jurídico. Diferentemente dessa sujeição, a Constituição do Brasil, oferece aos cidadãos brasileiros, ferramentas especiais que permitem uma nova forma de controle da Administração Pública mediante o efetivo exercício da cidadania.

Para Justen Filho (2005, p. 732), “o controle é um processo de redução do poder, entendida essa expressão no sentido da imposição da vontade e do interesse de um sujeito sobre outrem". Diz o autor que o controle pode ser de fiscalização ou de orientação da conduta alheia.

No estudo em pauta tem-se a submissão das atividades do Estado e de seus agentes, ao controle jurídico, por meio de instrumentos legais ofertados à sociedade e às instituições, além de instrumentos informais decorrentes do controle popular. Os mecanismos jurídicos decorrentes da Constituição Federal, como leis e regulamentos, chamados de controle de orientação, não substituem, porém, a participação popular 
decorrente do exercício da cidadania, que é um meio de controle-fiscalização e a mais adequada forma de se fazer a Democracia.

Na forma de controle institucionalizada, encontra-se, além do controle dos poderes, uns sobre as atividades dos outros, o Tribunal de Contas e o Ministério Público, no chamado sistema de freios e contrapesos do Estado de Direito, onde o próprio poder limita o poder, com atuações internas ou externas. Esse sistema de controle é chamado de controle político e nasceu da Teoria da Separação dos Poderes e, segundo lições de Carvalho Filho (2005, p. 729), tem por objetivo "a preservação e o equilíbrio das instituições democráticas do país".

Para parte da doutrina, o que chamam de controle político é matéria de Direito Constitucional, cabendo ao Direito Administrativo o controle das atividades da Administração Pública, por meio do chamado controle administrativo que se fundamenta no princípio da legalidade e no princípio das políticas administrativas.

Já Di Pietro (1999, p. 575) não faz tal distinção quanto às formas de controle, compreendendo a sua abrangência para os órgãos de todos os poderes, com a finalidade de "assegurar que a Administração atue em consonância com os princípios que lhe são impostos pelo ordenamento jurídico, como os da legalidade, moralidade, finalidade pública, publicidade, motivação, impessoalidade", abrangendo, inclusive, o controle de mérito.

Reconhece a autora (1999, p. 577) a participação dos administrados, ponto de interesse do presente trabalho; traz como conceito de controle administrativo "o poder de fiscalização e correção que a Administração Pública (em sentido amplo) exerce sobre sua própria atuação, sob os aspectos de legalidade e mérito, por iniciativa própria ou mediante provocação". (destaca-se)

Carvalho Filho $(2005$, p. 730 ) trás como conceito de controle da administração pública o "conjunto de mecanismos jurídicos e administrativos por meio dos quais se exerce o poder de fiscalização e de revisão da atividade administrativa em qualquer das esferas de Poder" (destaques do autor).

Embora sem um conceito enraizado, observa-se na doutrina mais recente um despertar para a modalidade de controle da Administração Pública pelo próprio cidadão, ora chamado de controle popular, ora tratado como controle social ou ainda controle participativo. 
Independente da denominação escolhida, todas as tratativas levam a análise pelo cidadão, das ferramentas que estão disponibilizadas pela Constituição do Brasil.

\section{Instrumentos de controle da administração pública pelo cidadão}

Não se pretende no presente estudo discorrer sobre as formas ou meios de controle abordados pela Constituição, mas antes de tudo, afirmar a sua existência e disponibilidade. Assim, antes de falar em cidadão, falar-se-á em administrado e na sua forma de atuação como controlador dos atos da Administração Pública. O ordenamento jurídico disponibiliza ferramentas que Di Pietro (1999, p. 578) chama, genericamente, de recursos administrativos, consubstanciando-os nos princípios constitucionais do contraditório e da ampla defesa, bem como no direito de petição.

É essa mesma fundamentação constitucional, que decorre dos direitos e garantias fundamentais abrangidos pelo Título II da Constituição, que faz do simples administrado, um cidadão, permitindo-Ihe valer-se do direito de petição para requerer a revisão, impugnar ou buscar informações sobre os atos praticados pelos agentes administrativos.

O cidadão brasileiro é aqui considerado, não apenas o eleitor, na forma trazida pela Lei no 4.717, de 29 jun. 1965, que regulamenta a ação popular, mas a pessoa humana, cuja dignidade vem a ser um dos pilares de sustentação da república, traduzindo-se em princípio fundamental. É esse cidadão que pode valer-se dos chamados remédios constitucionais como o Habeas Corpus; Habeas Data; Mandado de Injunção; Mandado de Segurança, individual ou coletivo; Ação Popular e Ação Civil Pública, todos eles já amplamente utilizados e estudados pelo Direito. É esse cidadão que pode mudar o Brasil.

Para o exercício do controle mediante os instrumentos citados, o cidadão tem à sua disposição o poder Judiciário. Este, também, independentemente da provocação do administrado, poderá, de ofício, exercer o controle da Administração Pública quanto à legalidade dos seus atos.

Conforme se depreende do conceito de controle formulado por Di Pietro, trazido ao presente estudo, vale a ressalva que apenas mais recentemente, estudiosos, doutrinadores e escassas decisões tribunalícias admitem o controle de mérito dos atos administrativos pelo poder Judiciário. Aqueles que assim o fazem, valem-se do princípio maior trazido pelo Art. 1으 e seu parágrafo único da Constituição Federal vigente, que instituiu um Estado Democrático 
de Direito consubstanciado na cidadania e dignidade da pessoa humana, atribuindo ao povo todo o poder.

Importante destacar que o direito de petição garantido pela Constituição Federal em seu Art. 5ㅇ, XXXIV, se constitui de um dos mais importantes instrumentos de cidadania. É por meio dele que o cidadão pode exercer a forma mais democrática de controle, pois nos dias atuais, não cabe mais ao direito de petição a interpretação restrita do passado. Pela sua utilização o particular pode obter junto à Administração Pública as informações de seu interesse de cidadão, não cabendo a essa a negativa ou restrições diante do dever de dar satisfações ao povo de quem está a serviço, sob pena de responsabilidade, inclusive penal, do administrador que assim o fizer. Sua negativa sem a devida e legal justificação se caracteriza em conduta abusiva contra o sistema democrático, importando em responsabilidade políticojurídica.

O poder constituinte quis que o administrado fosse cidadão. Cidadão que controla e que participa da Administração Pública na construção de uma nova sociedade. Ao promulgar a Constituição Federal de 1988, contemplou a participação pelos chamados institutos de democracia direta ou semidireta, onde se incluem o plebiscito, o referendo, a iniciativa popular de lei, as tribunas populares; os conselhos e outros canais de participação popular.

Não bastassem os instrumentos legais citados, o poder constituinte fundamentou a instituição do Estado Democrático de Direito, dentre outros princípios fundamentais, na dignidade da pessoa humana e na cidadania, cujo exercício permite o controle social.

Necessário se faz trazer à presente reflexão, o conceito jurídico de cidadania.

\section{Conceito de cidadania e o seu exercício}

Nas observações de Brito (2005):

no decorrer da historiografia brasileira, sete momentos foram fundamentais no desencadeamento da imagem brasileira atual: O "achamento" do Brasil, o período da cana-de-açúcar, o Período da mineração, a Independência do Brasil, a Proclamação da República, a Ditadura de Vargas e a Ditadura de 64. Todos estes contribuíram com marcas que de algum modo influenciaram e influenciam, ainda hoje, no comportamento da sociedade brasileira. Marcas que criaram dentro da consciência do indivíduo e da comunidade, em sua grande maioria, idéias distorcidas, errôneas, sobre o conceito, a função e a prática da cidadania, alimentando na mentalidade da sociedade brasileira, o pensamento de que os seus representantes carregam, junto ao seu mandato, a obrigação de praticar a 
cidadania para a população, diferente daquilo que está contido na Carta Magna Nacional.

Surge, então, a teoria da pseudotransferência de cidadania inerente à transferência de representatividade popular que revela o que é responsável, em grande parte, pela deteriorização da política nacional, já que demonstra que a criação da ilusão de que a cidadania é facultas agendi, ou seja, passível de escolha, propicia a falta de participação política popular, impossibilitando o cidadão de adquirir os seus direitos constitucionais.

A citação é ilustrativa, porém não se busca descer aos primórdios da história da humanidade para traçar o conceito de cidadania ou mesmo detalhar o seu desenvolvimento histórico traçado por Marshal (apud Cunha, 1981, p. 39-46), referendado e questionado por diversos autores sobre a sua aplicação ou não no Brasil.

Pretende-se abandonar os conceitos clássicos dos diversos e ilustres pensadores, onde cidadão era aquele que morava na cidade e participava de seus negócios ou aquela minoria que podia ter acesso a cargos públicos, bem como os marcos históricos trazidos pela Revolução Francesa e pela "Declaração dos Direitos do Homem e do Cidadão" para adentrarse na Constituição Brasileira, onde, conforme já citado, cidadania é fundamento da República Federativa do Brasil, existindo como a titularidade de direitos civis, políticos e sociais estabelecidos pelo Estado, tornando-se parte inerente e inseparável da Democracia, que tem como base o desenvolvimento da pessoa em liberdade, com a devida proteção das minorias.

A expressão da cidadania, resgatada pela Constituição brasileira, vai além de direitos, atingindo o sentido amplo de que a todo direito corresponde um dever, traduzindose no dever de participação na vida do País, em especial na utilização das ferramentas dispostas pela própria Constituição para exercer o controle do Estado. Em havendo dever, há sanções e estas, pelo não exercício da cidadania, traduzem-se na aceitação de um país conturbado e injusto como atualmente o Brasil se apresenta.

A presente afirmação faz com que se traga à colação, artigo publicado na Folha de Londrina, edição de 04 de dezembro, intitulado Eu Também Sou Culpado, onde o autor, Engenheiro Cláudio Espiga (2005, p. 02) de Londrina, traz as lições do pastor protestante Martin Niemiler, líder religioso alemão imortalizado na Segunda Guerra Mundial pela seguinte afirmação: 
Eles começaram perseguindo os comunistas e eu não protestei porque não era comunista. Depois, vieram buscar os judeus, e eu não protestei, porque não era judeu. Depois, ainda, vieram buscar os sindicalistas e eu não protestei porque não era sindicalista. Depois vieram me buscar. E já não havia ninguém para protestar.

Ao trazer tal citação o autor questionava sua própria omissão diante de fatos ocorridos em sua coletividade, ao mesmo tempo em que conclamava: "Vamos reagir! Não podemos aceitar mais nenhuma vítima!" O exemplo citado levou a uma séria reflexão sobre a omissão no exercício da cidadania, sobre a acomodação dos cidadãos diante de tantos instrumentos disponíveis, engolindo seus sapos e amedrontados diante do Estado-Poder, muitas vezes, por falta de informações adequadas, sem saber que o poder é seu e não do Estado. De igual força, o poema que ilustra o início deste trabalho.

O repensar para a efetividade da cidadania no Brasil não é apenas do citado articulista, mas de todos os brasileiros. Grandes alterações se fazem necessárias, em especial nos indicadores sociais e na distribuição de rendas, de sorte a permitir que não apenas aquela chamada "cidadania privilegiada" possa se valer da ampliação qualitativa trazida pela Constituição, com os novos institutos de democracia direta já citados, que visam a diminuir o desequilíbrio existente entre o povo e o Estado e sobre os quais se comentará, mas também àqueles hoje menos favorecidos, em especial pela educação.

A cidadania, no conceito que se quer para o presente trabalho, concede aos cidadãos o caráter de sujeitos de direito, livres e iguais perante a lei, mesmo com as questões de desigualdade por ela trazida, quanto aos direitos civis, por exemplo, ao estabelecer capacidades diferenciadas entre o analfabeto e o alfabetizado, que faz da cidadania um estatuto socialmente heterogêneo, provocando uma assimetria social em sua dimensão político-jurídica, nos dizeres de Cunha (1981, p. 39-46).

Interessa o conceito de cidadania onde o Estado capitalista se fez Estado Democrático de Direito, com a existência de uma ordem jurídica previsível, certa e segura, de sorte a permitir ao cidadão não apenas a participação pelo sufrágio, mas a segurança de atendimento a uma ordem jurídica da qual pode ter plena participação na sua própria elaboração, perdendo o seu papel de súdito.

Uma cidadania onde os direitos individuais não se limitam aos mais elementares, como os direitos à igualdade, à liberdade e à propriedade, dos quais se valiam apenas uma minoria, mas que cada cidadão possa ser o reivindicante e o construtor de sua própria 
administração, mediante a fruição total dos direitos individuais, sociais, políticos e econômicos que lhes são garantidos pelo ordenamento jurídico, não bastando apenas essa garantia, mas sua concretização e a implementação de todos os direitos garantidos (SILVEIRA, 2005).

Optou-se por trazer o conceito de Marshal (apud FEDOZZI, 1999), para quem “Cidadania se refere a tudo que vai desde o direito a um mínimo de bem-estar econômico e segurança ao direito de participar, por completo, na herança social e levar a vida de um ser civilizado de acordo com os padrões que prevalecem na sociedade".

\section{0 controle pela cidadania - meios possíveis}

Com os instrumentos de Democracia direta trazidos pela Constituição Federal, já relacionados, está o cidadão apto a cooperar com a Administração Pública e dela exigir. A atuação pode se dar, de forma mais fácil e mais próxima, diretamente junto aos Municípios, num exercício constante e num aprendizado eficaz. A participação em conselhos públicos municipais, ou ainda em conselhos autônomos permite a proximidade exigida. Faz-se necessária a reação, vez que, embora não exista qualquer vínculo de subordinação dos conselhos à Administração Pública, a tendência ao coronelismo ainda existe em alguns espaços, e o administrador busca a indicação dos conselheiros. Não se quer conselhos apadrinhados. Aqui se quer conselhos de cidadãos, livres e atuantes, na forma permitida pela Constituição. A Democracia é, pois, uma prática constante.

O que não se pode perder de vista é que, nada disso terá sentido ou, nada disso terá eficácia, se não for assegurado à coletividade o direito à informação. Como direito fundamental do cidadão, a Administração Pública tem o dever de informar à coletividade o que é de seu interesse, com as ressalvas excepcionais da lei para as questões por ela consideradas de sigilo.

A cidadania pode ser exercida como mecanismo transformador de uma sociedade. Todavia, esta mesma cidadania deve ser vista em todos os seus aspectos, principalmente no sentido que, por meio dela, se almeja uma sociedade com vida digna para todos.

Marshal (apud FEDOZZI, 1999), fala da importância da cidadania para a formação da consciência nacional. Diz o autor que: 
a cidadania exige um elo de liderança diferente, um sentimento de direito de participação numa comunidade baseado numa lealdade a uma civilização que é um patrimônio comum. Compreende a lealdade de homens livres, imbuídos de direitos e protegidos por uma lei comum. Seu desenvolvimento é estimulado tanto pela luta para adquirir tais direitos quanto pelo gozo dos mesmos, uma vez adquiridos.

Em artigo do professor da Faculdade de Direito de Campos, Weverson Viegas, o mesmo desenvolve algumas formas dos cidadãos exercerem o controle sobre o Estado mediante mecanismos horizontais e verticais.

Os mecanismos horizontais são os chamados "checks and balances", conhecidos no Brasil como sistema de freios e contrapesos, já tratado neste estudo, segundo o qual, um poder seria capaz de fiscalizar os outros. Interessa para o estudo os mecanismos verticais. 0 que interessa, nesse trabalho são os mecanismos horizontais, traduzidos nas eleições e a "democracia participativa". Esta, traduzida em participação popular, embora apresente um campo bastante propício de atuação, em especial nos Municípios, ainda busca atores relevantes que imponham a necessidade, o direito e o dever de suas participações junto à Administração Pública, de sorte a resultar em normas de vigência num estado de direito.

Tal reflexão impõe trazer o aclaramento do pensamento de Brito $(1997$, p. 85) que afirma:

\footnotetext{
a participação popular não quebra o monopólio estatal da produção do Direito, mas obriga o Estado a elaborar o direito de forma emparceirada com os particulares (individual ou coletivamente). E é justamente esse modo emparceirado de trabalhar o fenômeno jurídico, no plano de sua criação, que se pode entender a locução 'Estado Democrático' (figurante no preâmbulo da Carta de Outubro) como sinônimo perfeito de 'Estado Participativo.
}

Certamente será esse emparceiramento entre Estado e cidadão a que Brito se referiu é que trará a toda sociedade à melhoria das condições de vida da população, no que concerne às suas necessidades básicas e, em especial àquela que se entende ser a mola propulsora para a satisfação de todas as demais: a educação.

Com relação aos demais instrumentos de Democracia direta, tanto o plebiscito quanto o referendo são consultas feitas ao povo, para que este delibere sobre matérias relevantes de natureza constitucional, administrativa ou legislativa. 
O plebiscito caracteriza-se por consulta prévia à população, de determinada matéria que será posteriormente submetida à apreciação do Congresso Nacional, já tendo sido utilizado para definir a forma de governo adotada no Brasil.

Já o referendo é consulta posterior para a ratificação de ato governamental, como recentemente utilizada para a questão do porte de armas, cujo resultado foi uma demonstração incontestável da insatisfação do povo com seus governantes, merecendo aplausos pelo treinamento ao exercício da cidadania mencionado neste estudo.

Os instrumentos citados ainda precisam ser melhorados para se constituírem em instrumentos de cidadania no seu sentido amplo, abordando a todas as pessoas humanas e não apenas às pessoas eleitoras. Mas, reconhece-se que o primeiro passo foi dado.

Há que se falar, ainda, da iniciativa popular de lei, que poderá ser exercida pela apresentação, à Câmara dos Deputados, de projeto de lei subscrito por, no mínimo, um por cento do eleitorado nacional, devidamente distribuído por, pelo menos, cinco estados e com não menos de três décimos de eleitores de cada um deles. Aqui de bom tom a lembrança que a lei dos crimes hediondos decorreu de iniciativa popular encabeçada pela novelista Glória Perez.

Poder-se-ia, ainda, citar como mecanismo da participação popular na Administração Pública, a audiência pública e o orçamento participativo trazido pelo Estatuto da Cidade. Este último, parte do planejamento municipal, permite que o cidadão se manifeste sobre onde quer ver aplicado o dinheiro público. Para a sua utilização pelos Municípios, a Lei que o criou estabeleceu prazo de 5 (cinco) anos, a se expirar em 2006. No entanto, já são visíveis as movimentações de associações de bairros, conselhos e outros movimentos populares, acerca do referido instrumento que, sem reservas, será o grande instrumento do cidadão para o controle da Administração Pública, reiterando-se aqui, a necessidade de que o direito à informação seja efetivamente exercido, como instrumento de significativa importância para o desenvolvimento do Estado e da participação da pessoa no exercício da cidadania.

Sobre o tema ensina Graf (apud GUERRA):

O direito às informações de que o Estado dispõe fundamenta-se no princípio da publicidade dos atos administrativos e na eliminação dos segredos públicos. Neste sentido, o direito à informação constitui um indicador significativo dos avanços em direção a uma democracia participativa: oponível ao Estado, comprova a adoção do princípio da publicidade dos atos administrativos; sob o ponto de vista do cidadão, 
é instrumento de controle social do poder e pressuposto da participação popular, na medida em que o habilita para interferir efetivamente nas decisões governamentais e, se analisado em conjunto com a liberdade de imprensa e banimento da censura, também funciona como instrumento de controle social do poder.

Tantos outros instrumentos poderiam ser mencionados para exemplificar as possibilidades de participação popular, em especial a de forma autônoma, sem vínculo com a Administração Pública, de sorte a exercer plenamente a cidadania. No entanto, desnecessária se faz tal medida. A pessoa humana é dotada de inteligência e criatividade e certamente na medida em que suas necessidades se afloram, que injustiças se cometem, que direitos deixam de ser respeitados, novas modalidades de manifestação certamente surgirão. E terão elas os respaldos da Constituição que imprimiu em suas páginas que todo o poder emana do povo. É o que se avizinha para as futuras gerações que, de forma provável, poderão ver os seus governantes e seus representantes legislativos agirem de forma digna, sem exigência de extras e benesses.

\section{A participação do Tribunal de Contas ao apelo do cidadão}

Importante trazer a lume o papel dos Tribunais de Contas, órgão que atua como defensor dos direitos da sociedade quanto ao uso e aplicação pelo administrador de dinheiro, bens e valores públicos. Suas atribuições de controle constam dos Arts. 71 e seguintes da Constituição Federal.

No $\S 2$ do Art. 74, lê-se: “Qualquer cidadão, partido político, associação ou sindicato é parte legítima para, na forma da lei, denunciar irregularidades ou ilegalidades perante o Tribunal de Contas da União". (destacou-se)

Tal disposição, embora já exaurida a questão conceitual, permite que se traga como ilustração, o mais moderno conceito de controle da Administração Pública, da lavra de Guerra (apud COSTA, 2004, p. 323) diz ser:

a possibilidade de verificação, inspeção, exame, pela própria Administração, por outros poderes ou por qualquer cidadão, da efetiva correção na conduta gerencial de um poder, órgão ou autoridade, no escopo de garantir atuação conforme os modelos desejados e anteriormente planejados, gerando uma aferição sistemática. Trata-se, na verdade, de poder-dever de fiscalização, já que, uma vez determinado em lei, não poderá ser renunciado ou postergado, sob pena de responsabilização por omissão do agente infrator (destacou-se). 


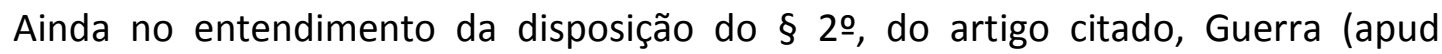
COSTA, 2004, p.323) conclui:

\begin{abstract}
Sem sombra de dúvidas este comando constitucional contido no art. 74 , § 2o fomenta, possibilita, legitima sobremaneira a participação popular no acompanhamento da execução dos planos de governo, o cumprimento de suas metas e a realização de despesas criando um canal aberto e constante de comunicação com o órgão técnico de controle.

Acredita-se que com uma sociedade organizada e participativa, um controle interno bem estruturado, qualificado e devidamente integrado entre os três Poderes e a postura firme, lúcida e tecnicamente apropriada dos Tribunais de Contas, participando em suas ações de controle em conjunto, quando possível, o Estado de Direito, democrático, sobretudo, estará garantido para as futuras gerações.
\end{abstract}

Com tais ensinamentos é possível deduzir que os Tribunais de Contas não são mais meras entidades coordenadas pelo Legislativo e fiscalizadores das questões financeiras do Executivo, mas verdadeiros instrumentos de cidadania à disposição para serem questionados quanto aos atos da Administração Pública.

\title{
7 Conclusão
}

Conclui o presente trabalho lembrando que a trajetória da humanidade, em todos os tempos, depara-se com a incessante luta pelo reconhecimento de direitos (direitos naturais, direitos civis, direitos políticos, direitos econômicos-sociais, direitos coletivos, sociais e difusos, direitos bioéticos...).

Além de reconhecer verdadeiro o provérbio jurídico "não basta ter direitos; é preciso poder exercê-los", do desenvolvimento do presente trabalho extraem-se as seguintes conclusões:

- o controle da Administração Pública é exigência legal, interna e externamente. Passa a ser, pela cidadania, a forma de participação do cidadão na administração do País, por meios de ferramentas específicas que a Constituição elencou como garantias fundamentais, inclusive na destinação da verba pública, dos orçamentos participativos.

- o conceito de cidadania evoluiu sobremaneira. Cidadania não abrange mais apenas o eleitor, como quer a lei da ação popular, que aqui se afirma não haver sido ela recepcionada pela Constituição do Brasil, face aos pilares fundamentais da república, inseridos em seu Art. 1 , que não distinguiu a pessoa humana do eleitor; 
- para os cidadãos brasileiros foram colocados diversos meios para o exercício de seus direitos fundamentais. Cabe a cada um impedir que tais meios não se tornem promessas vazias da lei. Mesmo que tais meios necessitem de aprimoramento, eles existem e são os instrumentos da verdadeira cidadania. Basta o exercício. Num primeiro momento, a afirmação parece por demais fácil de ser assimilada. É como se o texto imputasse ao cidadão uma crítica por não agir, pois afinal a ninguém é dado ignorar a existência da lei;

- vive o Brasil uma triste realidade. Excluídos de todos os gêneros, pela fome, pela seca, pela miséria, pela falta de educação, povoam a imensidão de seu território. Todos seres humanos, aos quais não se levam o mínimo de sobrevivência, muitos deles desconhecendo sequer a existência da Constituição, quanto mais os direitos que lhes são garantidos, por falta de informação. No entanto, são levadas a esses cidadãos, as informações sobre o exercício do voto, muitas vezes de forma manipulada;

- os fragmentos do poema de Eduardo Alves da Costa e artigos como o de Cláudio Espiga chamam a atenção. São os favorecidos pela educação se manifestando e conclamando outros favorecidos a lutar em nome dos excluídos, mesmo cientes de todos os obstáculos. E assim a corrente da cidadania adquirirá, a cada dia, um novo elo.

- dessa corrente, passou a ser parte importante, os Tribunais de Contas, que, na sua atuação, podem ser provocados pelos cidadãos, saindo da esfera exclusiva de controle financeiro.

E, em todos esses elos da corrente a esperança para a busca da verdadeira cidadania é depositada, almejando que, no seu exercício, o cidadão pratique o real controle da Administração Pública, de sorte que as ações dos administradores se sobreponham aos interesses particulares e garantam o bem maior encontrado no verdadeiro interesse público.

\section{Referências}

AGUILLAR, Fernando Herren. Controle Social de Serviços Públicos. São Paulo: Max Limonad, 1999.

BACELLAR FILHO, Romeu. Direito Administrativo. Coleção Cursos \& Concursos.

BONFIN, Edílson Mougenot (Coord.). São Paulo: Saraiva, 2005. 
BAPTISTA, Patrícia. Transformação do Direito Administrativo. Rio de Janeiro: Renovar, 2003.

BONTEMPO, Alessandra Grotti. Direitos Sociais: eficácia e acionabilidade à luz da Constituição de 1988. Curitiba: Juruá, 2005.

BRITO. Fernando de Azevedo Alves. Brasil: 500 anos de cidadania. [s. I.]. Disponível em: <http://jus2.uol.com.br/doutrina/texto.asp?id=2134>. Acesso em: 22 set. 2005.

CARVALHO FILHO, José dos Santos. Manual de Direito Administrativo. 13. ed. Rio de Janeiro: Lúmen Júris, 2005.

COSTA, Luiz Bernardo Dias. O Tribunal de contas. Sua Evolução e Principais Atribuições no Estado Democrático de Direito. In: Cenários Do Direito Administrativo. Estudos em Homenagem ao Professor Romeu Felipe Bacellar Filho. GUIMARÃES, Edgar (Coord.). Belo Horizonte: Fórum, 2004.

CUNHA, Rosa Maria Cardoso da. Restricões à vigência da cidadania no Estado Autoritário Brasileiro. In: REVISTA, v. 2, n. 3, p. 39-46, 1ㅇ semestre de 1981. Disponível em: <BuscaLegis.ccj.ufsc.br>. Acesso em: 11 nov. 2005.

DI PIETRO, Maria Sylvia Zanella. Direito Administrativo. 11. ed. São Paulo: Atlas, 1999.

ESPIGA, Engenheiro Cláudio. Eu Também Sou Culpado. Jornal Folha de Londrina, Londrina, Edição de 4 de dezembro de 2005.

FEDOZZI, Luciano. Orçamento Participativo. Observatório de Políticas Urbanas e Gestão Municipal (FASE/IPPUR), 1999.

FERRAZ, Luciano; MOTTA, Fabrício (Coord.). Direito Público Interno: homenagem ao professor Paulo Neves de Coelho. Belo Horizonte: Del Rey, 2003.

Fórum Administrativo - Direito Público - FA. ano 1, n. 1, mar. 2001. Belo Horizonte: Fórum, 2001.

GUERRA, Sidney. O direito à informação. In: Revista Ibero-Americana de Direito Público v. 05.

GUIMARÃES, Edgar (Coord.). Cenários do Direito Administrativo: estudos em homenagem ao Professor Romeu Felipe Bacellar Filho. Belo Horizonte: Fórum, 2004.

JUSTEN FILHO, Marçal. Curso de Direito Administrativo. São Paulo: Saraiva, 2005. 
ROCHA, Leonel Severo; STREEK, Lenio Luiz (Org.). Constituição, Sistemas Sociais e Hermenêutica. Programa de pós-graduação em Direito da UNISSINOS: mestrado e doutorado. Porto Alegre: Livraria do Advogado; São Leopoldo: UNISSINOS, 2005.

ROCHA, Valdir de Oliveira (Coord.). Aspectos Relevantes da Lei de Responsabilidade Fiscal. São Paulo: Dialética, 2001.

SILVA, José Afonso da. Curso de Direito Constitucional Positivo. 24. ed. São Paulo: Malheiros, 2005.

SILVEIRA, Cláudia Maria Toledo. Cidadania - Evolução Histórica. [s. I.]. Disponível em: <buscalegis.ccj.ufsc.br>. Acesso em: 14 out. 2005.

SOUSA, Alfredo José de; et al. O Novo Tribunal de Contas: órgão protetor dos direitos fundamentais. 2. ed. Belo Horizonte: Fórum, 2004.

VIEGAS, Weverson. Cidadania e Participação Popular. Faculdade de Direito de Campos dos Goytacazes. Disponível em: <buscalegis.ccj.ufsc.br>. Acesso em: 15 set. 2005. 
